\title{
Heparin-induced thrombocytopenia and endovascular procedures: report of two cases
}

\author{
Trombocitopenia induzida por heparina e tratamento endovascular: \\ relato de dois casos
}

\author{
Christiane Campolina Furquim Werneck, ${ }^{1}$ Allan Lossing, ${ }^{2}$ Thomas F. Lindsay ${ }^{3}$
}

\begin{abstract}
Heparin-induced thrombocytopenia (HIT) is a transient disorder caused by platelet-activating antibodies against platelet factor 4 (PF4)heparin complexes. Clinically, it translates into arterial or venous thrombosis and carries high morbidity and mortality. The use of large doses of heparin during endovascular repair of abdominal aortic aneurysm could increase the incidence of HIT. We report two cases associating the use of heparin during endovascular repair of abdominal aortic aneurysm with the development of HIT
\end{abstract}

Keywords: Heparin, heparin-induced thrombocytopenia, endovascular repair, abdominal aortic aneurysm.

\section{Introduction}

Heparin-induced thrombocytopenia (HIT) has become a well recognized allergic reaction, and with the broad use of heparin nowadays its importance is likely to increase. ${ }^{1}$ The low degree of recognition of its severe or delayed forms leads to a delay in diagnosis and institution of treatment, which can be associated with significant morbidity and mortality. Orthopedic, cardiac and vascular surgery patients exposed to prophylactic or therapeutic doses of heparin are at particular risk. As many as 50 to $60 \%$ of cardiac surgery patients form HIT antibodies after exposure to heparin. ${ }^{2}$ With the common practice of priming endografts during endovascular aneurysm repair (EVAR) of infrarenal abdominal aortic aneurysm (AAA) with high concentration heparin solution, the incidence of HIT may increase. Here, we present two cases in which this association was positive, with serious clinical consequences.

\section{Resumo}

Trombocitopenia induzida por heparina (TIH) é um distúrbio transitório causado pela ativação de anticorpos antiplaquetários contra o fator plaquetário 4 (FP4) combinado com a molécula de heparina, formando complexos que clinicamente se traduzem em tromboses arteriais ou venosas com alta morbimortalidade. O uso de altas doses de heparina durante procedimentos endovasculares para o tratamento de aneurisma de aorta abdominal pode aumentar a incidência de TIH. Relatamos dois casos em que o uso de heparina durante tratamento endovascular de aneurisma de aorta abdominal estava associado ao aparecimento de TIH.

Palavras-chave: Heparina, trombocitopenia induzida por heparina, tratamento endovascular, aneurisma de aorta abdominal.

\section{Case 1}

An 83 year-old male had an elective EVAR of an infrarenal AAA. At the time of the procedure, 10,000 IU of unfractionated heparin (UFH) were used to prime a Zenith ${ }^{\circledR}$ bifurcated stent-graft (Cook, Inc, Bloomington, IN, USA), and 7,000 IU of UFH were used to anticoagulate the patient systemically. The postoperative course was uneventful, and he was discharged within 2 days. He developed symptoms of acute ischemia of the right leg 14 days after the procedure. At the emergency department, he presented with cold pulseless right leg; left leg was unremarkable. UFH was initiated and a computerized tomography angiogram (CTA) showed patent endograft and a $2.0 \mathrm{x}$ $2.0 \mathrm{~cm}$ thrombosed right popliteal aneurysm with outflow through the posterior tibial artery (Figure 1). As past medical history, he had: hypertension, hypercholesterolemia, cardiac pacemaker (heparin might have been used) and no prior history of hypercoagulable state.

\footnotetext{
1. Assistant professor, Department of Surgery, Division of Vascular Surgery, Trillium Health Centre and Credit Valley Hospital, University of Toronto, Toronto, Ontario, Canada.

2. Associate professor of Surgery, Department of Surgery, Division of Vascular Surgery, Saint Michael's Hospital, University of Toronto, Ontario, Canada.

3. Professor of Surgery, Department of Surgery, and Chair, Division of Vascular Surgery, Toronto General Hospital, Program Director, University of Toronto, Ontario, Canada.

No conflicts of interest declared concerning the publication of this article. Manuscript received Dec 15 2008, accepted for publication Apr 282009.

J Vasc Bras. 2009;8(3):259-262.

Copyright $@ 2009$ by Sociedade Brasileira de Angiologia e de Cirurgia Vascular
} 


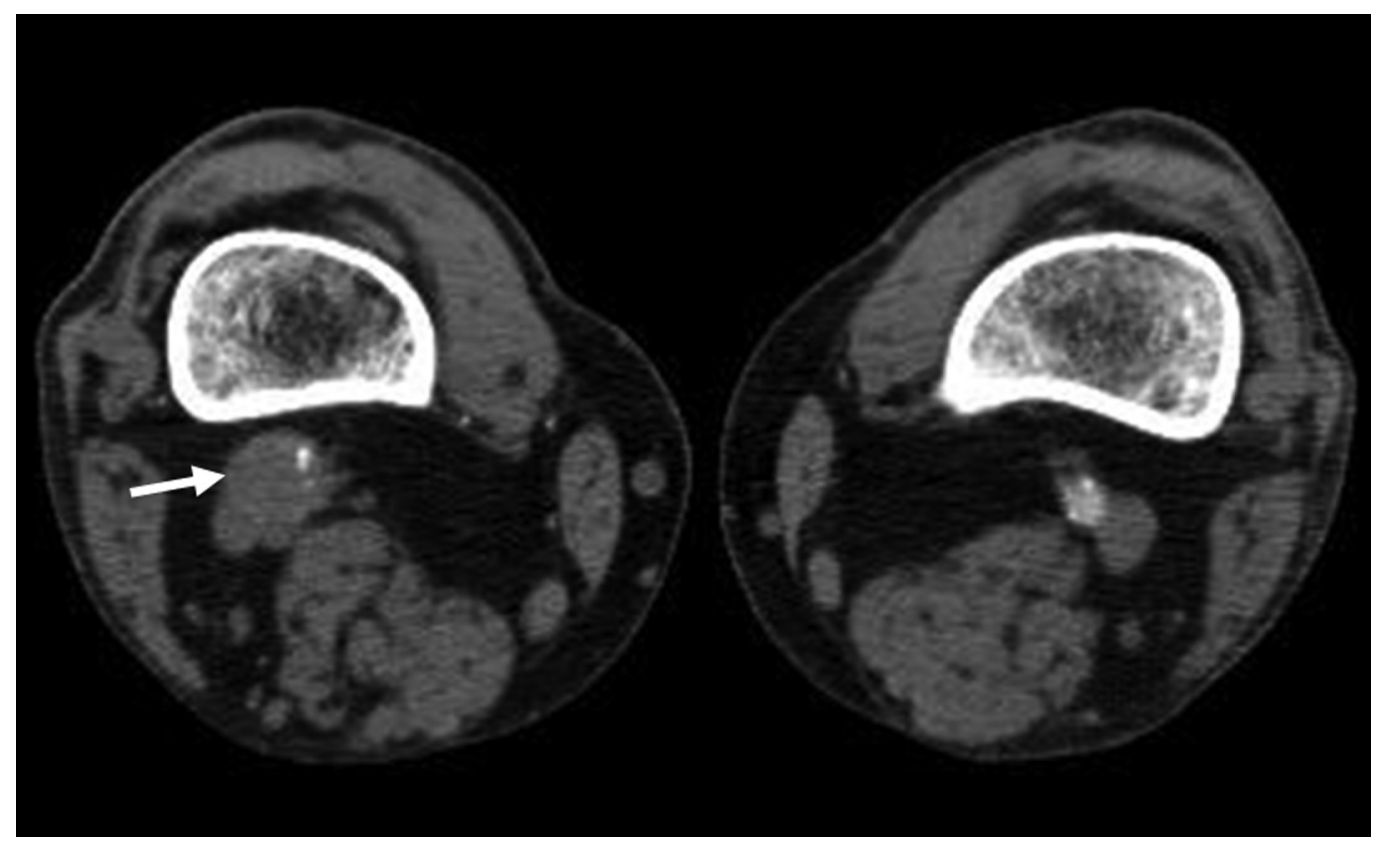

Figure 1 - First case reported: computerized tomography angiogram on admission showing the thrombosed right popliteal artery aneurysm (arrow) occurred in the postoperative course of endovascular aneurysm repair

More UFH was administered according to his weight during a bypass procedure performed to reperfuse his right leg, at the end of which the vein graft had to be revised due to inadequate flow and thrombus formation diagnosed by duplex scan. From his admission until the end of the procedure, his platelets dropped significantly (Figure 2), and added to his hypercoagulable state seen during the procedure despite the use of UFH. HIT was suspected. Meanwhile, the UFH was stopped and argatroban was initiated. The HIT assays came back positive for anti-platelet factor 4 (PF4) antibodies and, after a few days, his platelet counts returned to the normal range. At discharge, the patient took oral anticoagulant (warfarin) and had a patent bypass. At

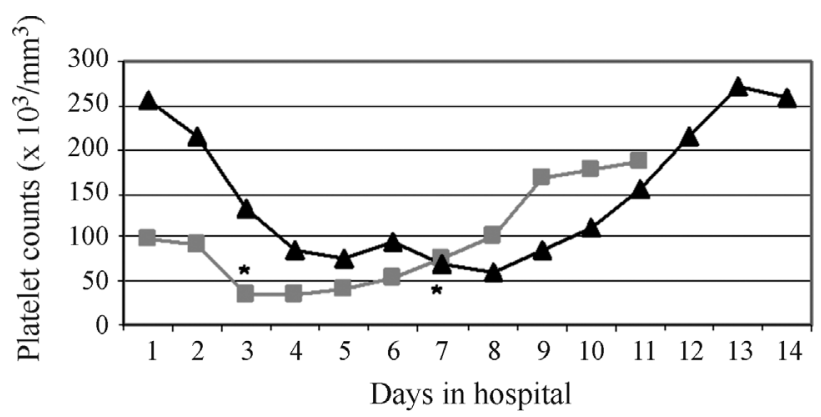

*Indicates when the diagnosis of heparin-induced thrombocytopenia was suspected and subsequently confirmed by assays.

Figure 2 - Platelet counts over the clinical course
6 months of follow-up, his venous graft and endograft remained patent on CTA.

\section{Case 2}

A 72 year-old female underwent an uneventful EVAR of an AAA. During the procedure, 10,000 IU of UFH were used to prime a Zenith ${ }^{\circledR}$ bifurcated stent-graft (Cook, Inc, Bloomington, IN, USA), and 5,000 IU of UFH were given systemically to provide adequate anticoagulation. Completion angiogram documented graft patency, and the patient was discharged within 2 days. Fourteen days post EVAR, she presented with sudden onset of moderate right leg pain which evolved over the next 4 days to rest pain and hypoesthesia of the right foot. Her past medical history was: severe chronic obstructive pulmonary disease, hypertension, osteoporosis, arthritis and depression, all of those controlled with medications. She denied any prior diagnosis of hypercoagulable state, history of atrial fibrillation or previous exposure to heparin, although she had history of a gynecological procedure under general anesthetic.

She was re-admitted with a severe ischemia of the right leg with neurological impairment; her left leg was unremarkable. CTA showed occlusion of the distal portion of the main body and right limb of the endograft. Distally to that, the right common iliac artery was filling through retrograde flow from the internal iliac artery. No distal 
thrombosis was seen. A mild kink at the endograft with mild to moderate stenosis of the right iliac artery was thought to be the cause of the acute thrombosis. Immediately, the patient was anticoagulated with UFH. Intraarterial thrombolysis with recombinant t-PA $(2 \mathrm{mg} / \mathrm{h})$ in association with UFH (500 IU/h) was performed for a few hours with successful recanalization. Angioplasty of the right common iliac artery was performed, and final angiogram confirmed good results. Due to large retroperitoneal hematoma, both recombinant t-PA and UFH were interrupted; the latter was restarted after a few hours. The low platelet count at the time was attributed to the hematoma. UFH was restarted, the platelet count started to decline again. Further imaging was performed to rule out active bleeding. The diagnosis of HIT was suspected and confirmed by the presence of PF4 antibodies by ELISA test. UFH was immediately stopped and argatroban was initiated with normalization of platelet count in a few days (Figure 2). The patient was discharged from the hospital on warfarin and with a patent endograft. The endograft remains patent and unchanged 12 months after the original procedure, as confirmed by CTA.

\section{Discussion}

HIT is a potentially life-threatening disease, and the number of confirmed cases has increased dramatically since it was first described with the use of unfractionated heparin. $^{3}$ The exposure to large doses of heparin, as seen during on-pump cardiac surgery, increases the incidence of antibody formation and consequently the chance of developing thrombotic events. ${ }^{4}$ The use of UFH during endovascular procedures is likely to place this therapeutic modality as a potential contributing factor to this increase in incidence. A high index of suspicion is necessary for the diagnosis and timely institution of treatment. Two types of HIT have been described: type I is the severe form, which occurs early and results in a benign course with recovery of the platelet count even with continued heparin therapy. Type II, a delayed form, occurs between 5-14 days after institution of heparin therapy without previous exposure or after 3-9 days with previous exposure. The mechanism of action of the two forms is different: in type $\mathrm{I}$, the effect of heparin on the platelets causing aggregation is nonimmune-mediated, and in type II there is an immune-mediated (IgM and $\mathrm{IgG}$ ) platelet aggregation. When the heparin is bounded to the platelet, antibodies against PF4 are produ- ced and activated, resulting in increased thrombin formation and possible thrombotic complications. Type II HIT has high morbidity (23-60\%) and mortality rates (12-18\%). Approximately half of the patients with Type II HIT will develop thrombotic events, the majority of them being venous events. ${ }^{1,4}$ Early recognition of the syndrome is known to reduce morbidity and mortality, ${ }^{5}$ but requires a high index of suspicion ("4 Ts", Thrombocytopenia, Timing, Thrombosis and exclusion of other causes). The presence of antibodies against platelet factor 4 confirms the diagnosis. Treatment starts with the immediate interruption of heparin and early institution of the appropriate nonheparin anticoagulant solely based on the clinical suspicion, until the HIT antibody tests are available. ${ }^{1,6,7} \mathrm{~A}$ variety of anticoagulants have been used in patients with HIT including warfarin, low molecular weight heparin (LMWH), and heparin-like agents such as danaparoid sodium. ${ }^{6,8,9}$ It is known that warfarin has a risk of causing venous gangrene and skin necrosis when started in the acute phase of HIT. However, it should be started after the platelet count returns to its normal level $\left(>150.000 / \mathrm{mm}^{3}\right)$ overlapping with alternative anticoagulation (minimum 5-day overlap), beginning with low, maintenance doses (maximum of $5 \mathrm{mg}$ ), and continued for 3-6 months after an arterial or venous thrombotic episode. ${ }^{7,8}$ LMWH has a high risk (about 50\%) of thrombocytopenia or thrombosis if used to treat HIT because of cross-reactivity with HITIgG. Danaparoid has been used, although it shows crossreactivity (in vitro) in 10 to $20 \%$ of patients with HIT. $^{6}$ It is the standard of practice to start direct thrombin inhibitors such as argatroban and lepirudin (both approved by the FDA) (Table 1). Both can inhibit soluble and clot-bound thrombin and have short half-lives (about 40 to 80 minutes). Lepirudin is renally metabolized, whereas argatroban is metabolized by the liver. Both agents - but specifically argatroban - increase the international normalized ratio (INR), which can complicate overlapping argatroban/warfarin therapy. Ideally, the INR should be above 4 before argatroban is discontinued to avoid warfarin-induced venous limb gangrene. ${ }^{9,10}$

Cases of HIT related to EVAR are very rare. We are aware of a single case report which presented as an endograft thrombosis. ${ }^{11}$ In both of our cases, the drop in platelet count and time of presentation were the main hints for the diagnosis. In our first case, they were added to the presen- 
Table 1 - Direct thrombin inhibitors currently used for the treatment of HIT

\begin{tabular}{|c|c|c|}
\hline Anticoagulant & Therapeutic dosing & Comments \\
\hline Argatroban & $\begin{array}{l}\text { Initial infusion } 2 \mu \mathrm{g} / \mathrm{kg} / \mathrm{min} \text { (no bolus); sub- } \\
\text { sequent dose adjusted by aPTT; patients with } \\
\text { or at risk of HIT undergoing percutaneous } \\
\text { cardiac intervention require higher doses }\end{array}$ & $\begin{array}{l}\text { Monitored by aPTT (target } 1.5 \text { to } 3.0 \text { times base- } \\
\text { line, not to exceed } 100 \mathrm{~s} \text { ). Increases INR, ACT and } \\
\text { PT. Does not develop drug-specific antibodies. }\end{array}$ \\
\hline Lepirudin (recombinant hirudin) & $\begin{array}{l}0.4 \mathrm{mg} / \mathrm{kg} \text { over } 15 \text { to } 20 \text { seconds as a bolus } \\
\text { dose, followed by a constant infusion of } \\
0.15 \mathrm{mg} / \mathrm{kg} / \mathrm{h}\end{array}$ & $\begin{array}{l}\text { Monitored by aPTT (target } 1.5 \text { to } 2.5 \text { times baseline); } \\
\text { antihirudin antibodies could develop, altering antico- } \\
\text { agulant effect. It is relatively contraindicated in renal } \\
\text { failure. Anaphylactic reaction and death can occur. }\end{array}$ \\
\hline Bivalirudin & $\begin{array}{l}\text { Initial infusion } 0.15 \text { to } 0.20 \mathrm{mg} / \mathrm{kg} / \mathrm{h} \text { (no ini- } \\
\text { tial bolus); subsequent dose adjusted by } \\
\text { aPTT }\end{array}$ & $\begin{array}{l}\text { Monitored by aPTT (target } 1.5 \text { to } 2.5 \text { times base- } \\
\text { line); } 80 \% \text { enzymic metabolism suggests it may } \\
\text { have advantages for patients with combined renal } \\
\text { and hepatic dysfunction. }\end{array}$ \\
\hline
\end{tabular}

$\mathrm{ACT}=$ activated clotting time; aPTT $=$ activated partial thromboplastin time; $\mathrm{HIT}=$ heparin-induced thrombocytopenia; INR $=$ international normalized ratio; $\mathrm{PT}=$ prothrombin time.

ce of hypercoagulable state during bypass surgery. In the second, the kink in the right iliac artery may have caused the graft thrombosis. Due to early recognition and diagnosis, both patients had no other clinical consequences.

Major endovascular procedures require the use of large doses of heparin and currently there is no way of identifying, among patients with higher risk, those who will develop HIT antibodies. Therefore, a high index of clinical suspicion is necessary. Further improvement in EVAR technology may address this problem, maybe creating alternatives for the need and type of anticoagulation.

In conclusion, heparin-induced thrombocytopenia is a rare adverse reaction after endovascular procedures that can have devastating consequences. The increasing number of major endovascular procedures in which large amounts of heparin are required is likely to increase its occurrence. A high index of suspicion is necessary in order to recognize it and institute proper therapy.

\section{References}

1. Warkentin TE. Heparin-induced thrombocytopenia: diagnosis and management. Circulation. 2004;110:e454-8.

2. Bartholomew JR. The incidence and clinical features of heparin-induced thrombocytopenia. Semin Hematol. 2005;42:S3-8.

3. Shuster TA, Silliman WR, Coats RD, et al. Heparin-induced thrombocytopenia: twenty-nine years later. J Vasc Surg. 2003;38:1316-22.
4. Warkentin TE, Kelton JG. A 14-year study of heparininduced thrombocytopenia. Am J Med. 1996;101:502-7.

5. Warkentin TE, Chong BH, Greinacher A. Heparin-induced thrombocytopenia: towards consensus. Thromb Haemost. 1998;79:1-7.

6. Hirsh J, Heddle N, Kelton JG. Treatment of heparin-induced thrombocytopenia: a critical review. Arch Intern Med. 2004;164:361-9.

7. Keeling D, Davidson S, Watson H; Haemostasis and Thrombosis Task Force of the British Committee for Standards in Haematology. The management of heparin-induced thrombocytopenia. Br J Haematol. 2006;133:259-69.

8. Warkentin TE, Greinacher A. Heparin-induced thrombocytopenia: recognition, treatment, and prevention: the Seventh ACCP Conference on Antithrombotic and Thrombolytic Therapy. Chest. 2004;126(3 Suppl):311S-37S.

9. Warkentin TE, Greinacher A, Koster A, Lincoff AM; American College of Chest Physicians. Treatment and prevention of heparin-induced thrombocytopenia: American College of Chest Physicians Evidence-Based Clinical Practice Guidelines (8th Edition). Chest. 2008;133(6 Suppl):340S-80S.

10. Alberio L. Heparin-induced thrombocytopenia: some working hypotheses on pathogenesis, diagnostic strategies and treatment. Curr Opin Hematol. 2008;15:456-64.

11. Chuter TA, Pak LK, Gordon RL, Reilly LM, Messina LM. Heparin-induced thrombocytopenia and graft thrombosis following endovascular aneurysm repair. J Endovasc Ther. 2003;10:1087-90.

Correspondence:

Christiane C. F. Werneck, MD, RVT

200 Elizabeth Street 6EN-306

M5G 2C4 - Toronto, ON - Canada

Tel.: +1 (416) 340.4620

Fax: +1 (416) 340.5029

E-mail: chriswerneck@gmail.com 